\title{
ANTROPOLOGIA PARTILHADA E MONTAGEM DO FILME ETNOGRÁFICO: NARRATIVA SOBRE O PROCESSO DE REALIZAÇÃO DE «BRAVO»
}

\author{
ALFREDO M. PONTES ${ }^{1}$
}

\begin{abstract}
RESUMO
A partir da realização do filme etnográfico "BRAVO»² (2017), este artigo propõe uma discussão acerca do processo de montagem desta experiência fílmica pensando em uma antropologia partilhada. Representar 0 outro é sempre muito difícil, ainda mais quando esta representação dá-se através de uma câmera, seja ela fotográfica ou fílmica. Como representar a vida de alguém a partir de imagens e como este alguém quer ser visualmente representado? Através do dispositivo fílmico e da etnografia visual, qual linguagem utilizar neste processo de representação sem desempoderar ou exotizar quem está a ser representado?
\end{abstract}

\section{PALAVRAS-CHAVE}

Filme etnográfico; montagem; antropologia partilhada.

\section{SHARED ANTHROPOLOGY AND SCREEN PLAY OF AN ETNIGRAPHICAL MOVIE:NARATIVES ABOUT THE PROCESS OF FILMAKING OF "BRAVO"}

\begin{abstract}
Taking as a subject the ethnographic film "BRAVO» (2017), this article aims to discuss the creative process behind the movie through a shared anthropological approach. It is always difficult to portrait the other, even more so when this portrait is accomplished though the lens of a camera, being it a filming one or not. How is one supposed to represent someone's life though images and in which way does that someone want to be represented? Through the use of film and visual ethnography, which language should one use in order to represent someone without exoticizing or diminishing the person who is being represented?
\end{abstract}

\section{KEYWORDS}

Ethnographic film; montage; shared anthropology.

\footnotetext{
${ }^{1}$ Licenciado em Ciências Sociais pelo Instituto de Ciências Sociais da Universidade Federal de Alagoas (ICS/UFAL). Mestrando em Antropologia com especialização em Culturas Visuais na Faculdade de Ciências Sociais e Humanas da Universidade Nova de Lisboa (FCSH/UNL) e é aluno da especialização em Discursos da Fotografia Contemporânea da Faculdade de Belas Artes da Universidade de Lisboa (FBA/UL). Membro do Laboratório Antropologia Visual em Alagoas (AVAL). E-mail: alfredompontes@gmail.com.
}

${ }^{2}$ Filme (disponível no Vimeo) apresentado como trabalho final à disciplina de Atelier de Imagem, do mestrado em Antropologia com especialização em Culturas Visuais da Faculdade de Ciências Sociais e Humanas da Universidade Nova de Lisboa (FCSH/UNL), orientado pela antropóloga visual Inês Mestre, colaboradora do Núcleo de Antropologia Visual e da Arte do Centro em Rede de Investigação em Antropologia (NAVA/CRIA). 


\title{
ANTHROPOLOGIE PARTAGÉE ET LA MISE EN SCÈNE D'UN FILM ETHNOGRAPHIQUE: NARRATIVES SUR LE PROCESSUS DE CONSTRUCTION DE « BRAVO »
}

\begin{abstract}
RÉSUMÉ
A partir de la réalisation du film ethnographique «BRAVO» (2017), cet article propose une discussion à propos du processus de montage de cette expérience filmique en pensant à une anthropologie du partage. Il est toujours très difficile de représenter l'autre, surtout quand cette représentation se fait à travers la caméra, qu'elle soit photographique ou filmique. Comment représenter la vie d'une personne à partir d'images et comment cette personne veut-elle être visuellement représentée? A travers le dispositif filmique et de l'ethnographie visuelle, quel langage utiliser dans ce processus de représentation sans contraindre ou exotiser celui qui est représenté?
\end{abstract}

\section{MOTS-CLÉS}

Film ethnographique; montage; anthropologie du partage.

\section{ANTOPOLOGÍA COMPARTIDA E EL MONTAJE DE LA PELIICULA ETNOGRÁFICA: NARRATIVA SOBRE EL PROCESO DE REALIZACIÓN DE "BRAVO"}

\section{RESUMEN}

Tras la realización de la película etnográfica «BRAVO» (2017), este artículo propone un debate acerca del proceso de montaje de esa experiencia cinematográfica pensando en una antropología compartida. Reproducir el otro es siempre muy difícil, además cuando la representación es por las cámaras, de fotografía o cine. ¿Cómo reproducir la vida de alguien a partir de imágenes y cómo ese alguien piensa ser reproducido? Con el dispositivo cinematográfico y la etnografía visual, ¿cuál lenguaje podríamos utilizar en este proceso de representación sin desapoderarlos o hacerlos exóticos a aquellos que son representados?

\section{PALABRAS-CLAVE}

Película etnográfica; montaje; antropología compartida. 


\section{INTRODUÇÃO}

Fernanda Bravo é quem está a ser representada no filme «BRAVO» (2017). Fernanda, 47 anos, é uma mulher transexual, brasileira, imigrante no continente europeu, trabalhadora sexual e artista/performer do grupo TRANSHOW. Conheci-a em dezembro de 2014 no Teatro de Arena, em Maceió, Alagoas (Brasil), em seu primeiro espetáculo como integrante do TRANSHOW, e no meu primeiro dia como fotógrafo voluntário do mesmo grupo.

O grupo artístico TRANSHOW é uma entidade sem fins lucrativos sediada em Maceió, Alagoas, formada por travestis e transexuais. O grupo foi fundado em 2014 pela militante e artista Natasha Wonderfull (vice-presidenta da Associação das Travestis e Transexuais de Alagoas [ASTTAL]) e tem como objetivo dar visibilidade às transexuais e travestis do Estado de Alagoas, criando um espaço de inclusão sociocultural através do viés artístico (SILVA, 2016, p. 78).

Entre os anos de 2014 e 2016, acompanhei Fernanda em alguns espetáculos e criamos um vínculo afetivo que nos manteve em contato até então. Simultaneamente, fui criando um acervo de registros fotográficos e fílmicos acerca não só de Fernanda, como também de todo o grupo. Entre fevereiro e julho de 2016, tive a acompanhar e filmar mais um espetáculo do TRANSHOW e encontrei-me novamente com Fernanda. Neste encontro ela disse-me que ia voltar para Portugal ${ }^{3}$ por uma temporada. De fato, Fernanda saiu do Brasil poucos meses depois.

Em Portugal vimo-nos no mesmo dia que ela chegou do Brasil, em Outubro de 2016. Mesmo ela estando maioritariamente no norte do país, estivemos constantemente em contato, pois, periodicamente, ela vinha a consultas médicas em um hospital no centro de Lisboa ${ }^{4}$, o que facilitava os nossos encontros.

Nós - eu e Fernanda - já havíamos discutido sobre a possibilidade de realizarmos algum filme para podermos aproveitar o material que tive a filmar de seus espetáculos no TRANSHOW ao longo dos últimos anos, mas só viemos a objetivar isto em Abril de 2017, quando durante o meu segundo semestre do mestrado em Antropologia foi-me sugerido o exercício de representar o outro através do dispositivo fílmico.

\footnotetext{
${ }^{3}$ Fernanda, enquanto trabalhadora sexual, esteve durante grandes períodos de tempo a viver no continente europeu, nomeadamente em Portugal e Itália, dentre outros países. Em 2016, fazia cerca de 5 (cinco) anos em que ela estava de volta ao Brasil.

${ }^{4}$ De acordo com a Constituição da República Portuguesa e da Lei de Bases da Saúde, todas/os as/os imigrantes têm o direito e o dever de proteção da sua saúde em Portugal. O despacho 25360/2001 garante o acesso à saúde a qualquer pessoa nesta condição, independentemente do seu estatuto jurídico (BÄCKSTRÖM; CARVALHO; INGLÊS, 2009, p. 168).
} 
Era início de Maio e Fernanda estava prestes a viajar para a França, sem previsão de volta a Portugal. Antes da viagem, ela inevitavelmente iria passar por Lisboa porque tinha uma consulta médica marcada. Combinamos que iríamos nos encontrar para tentarmos produzir alguma coisa - ou apenas nos encontrar antes da sua viagem. A princípio, pensamos em um plano de rodagem em que seriam feitas apenas imagens dela no período pré e pósconsulta médica, que, posteriormente, iriam dialogar com o arquivo imagético produzido desde o nosso primeiro encontro, em 2014. Entretanto pensei que filmá-la fora de seu ambiente mais íntimo e subjetivo - naquela altura, o seu quarto temporário - pudesse trazer alguma carência ao filme, o que motivou-me a ir encontrá-la no norte do país, em Paredes 5 .

\section{Fernanda, A CÂMERA E EU}

Quase oito da manhã do dia três de Maio de dois mil e dezessete. Bati à porta. Ainda sonolenta Fernanda levantou-se, abriu-me rapidamente a porta e voltou a deitar-se. Liguei a câmera quando ela ainda estava na cama a despertar e comecei a filmar os seus primeiros movimentos do dia, enquanto conversávamos descontraidamente sobre coisas cotidianas. Apesar de já ser dia, a casa estava muito escura porque todas as janelas ainda estavam fechadas. Por hábito, perguntei-lhe como estava e ela disse-me que estava cansada e tinha estado muito ansiosa e estressada, por isso marcou a consulta médica em Lisboa antes da sua viagem. Em uma das nossas conversas, que está incluída no filme (3'25"), ela conta do seu dia-a-dia em Paredes e expressa com pesar o fato de ultimamente estar a passar demasiado tempo sozinha por conta da sua rotina exaustiva de trabalho.

Era o último dia de Fernanda naquela cidade, por isso ela teve que pedir autorização à responsável da casa para ficar mais algumas horas ali porque estava a minha espera. Combinamos em passar algum tempo na casa a conversar e a filmar e, logo em seguida, íamos para o Porto encontrar com a sua amiga, Soraya, para, finalmente, voltarmos a Lisboa. Ao longo deste dia os diálogos giravam em torno de assuntos como a solidão que ela sentia condicionada pelo seu trabalho, da sua sorologia e do acesso aos medicamentos retrovirais em Portugal, alguns aspectos da sua vida como imigrante no continente europeu, a sua vontade constante em querer retornar ao Brasil por ter saudade da família, dentre outras subjetividades que me fizeram sentir uma ainda maior empatia por ela - sendo esta relação essencial para a captação das imagens apresentadas no filme.

Рara a antropóloga e artista visual Lydia Nakashima Degarrod (2013), o processo de empatia é fundamental no âmbito da pesquisa etnográfica e/ou na realização de um trabalho artístico colaborativo, ao passo em que torna-se um elemento bastante importante no desenvolvimento do relacionamento com os indivíduos que fazem parte da pesquisa. A

\footnotetext{
${ }^{5}$ Paredes é um concelho da região norte de Portugal, integrada à Área Metropolitana do Porto.
} 
autora elaborou a exposição "Geographies of the Imagination" (2008), que retrata a vida de exílio a longo prazo de um grupo de nove (9) exiladas/os politicos chilenos que vivem na Baía de São Francisco (EUA) e migraram entre 1973 e 1980 durante a ditadura militar na República do Chile (1973-1990), sob o governo autoritário do ex-general Augusto Pinochet. O trabalho reflete sobre a vida destas pessoas e as suas relações descontínuas com o tempo e espaço por questões políticas. Pensando neste sentido, a relação afetiva que eu e Fernanda estabelecemos ao longo do processo fílmico foi fundamental para determinar o produto audiovisual final.

Como forma de evitar um fatal distanciamento e enfatizar a relação de proximidade que desenvolvemos desde o nosso primeiro encontro, durante a maior parte da rodagem optei por não utilizar o tripé. Jean Rouch, em uma entrevista concedida a Jean-Paul Colleyn em 1992, explica o quão limitador pode ser o uso do tripé por forçar-lhe a fixar-se a um ponto de vista único (ROUCH, 1995, p. 65). Assim, a não-utilização do tripé possibilitou-me pensar novas dinâmicas de filmagem e diferentes modos de interação entre eu, Fernanda e a câmera.

A nossa forma de comunicação passou a ser bem mais intensa e direta, sendo este encontro registrado pela câmera que estava quase sempre na minha mão e poucas vezes no tripé. A câmera tinha uma importância fundamental não apenas a nível prático e técnico, mas também a nível sensível e subjetivo. Nos dias de rodagem foi a câmera que muitas vezes mediou e estreitou a minha relação com Fernanda. Naqueles momentos, o equipamento videográfico podia ser interpretado como uma extensão do meu corpo que dialogava com o corpo de Fernanda, evidenciando muitas vezes o que Rouch chamou de ciné-transe (ROUCH, 1995, apud RUSSELL, 1999, p. 218-220).

A naturalização da presença da câmera por parte da Fernanda parecia ter sido quase que imediata. Às vezes sentia que talvez esta "naturalização" fosse mais um processo meu enquanto alguém que estava a experimentar possibilidades através da imagem em movimento - do que dela - a pessoa que estava a ser representada filmicamente, no sentido em que, inicialmente, não me sentia muito confortável em estar a filmá-la - temia estar sendo demasiadamente invasivo. Aos poucos fui ficando mais à vontade em estar ali e assumindo o meu suposto papel enquanto etnógrafo visual - representá-la através do dispositivo fílmico.

Eventualmente eu perguntava se ela queria que eu desligasse a câmera ou se algo estava a incomodá-la. Contrariamente, ela deixava-me cada vez mais confortável e às vezes parecia até esquecer da presença daquele objeto. O meu receio inicial em capturar tais imagens remete-me ao momento em que a antropóloga visual Sylvia Caiuby Novaes (2012) experienciou com indígenas do Mato Grosso, no Centro-Oeste do Brasil A antropóloga, em um texto que discorre sobre a sua pesquisa com a comunidade Bororó, expressa sensações e 
cuidados semelhantes quando fotografou rituais do grupo, ressaltando a importância da negociação e o estabelecimento de um vínculo de confiança com as pessoas que estão a ser fotografadas. Estes dois elementos - a negociação e a confiança, quando conjugados de forma harmoniosa e ética, são peças fundamentais para que haja um fluxo mais genuíno no processo de representação através da câmera fotográfica ou videográfica.

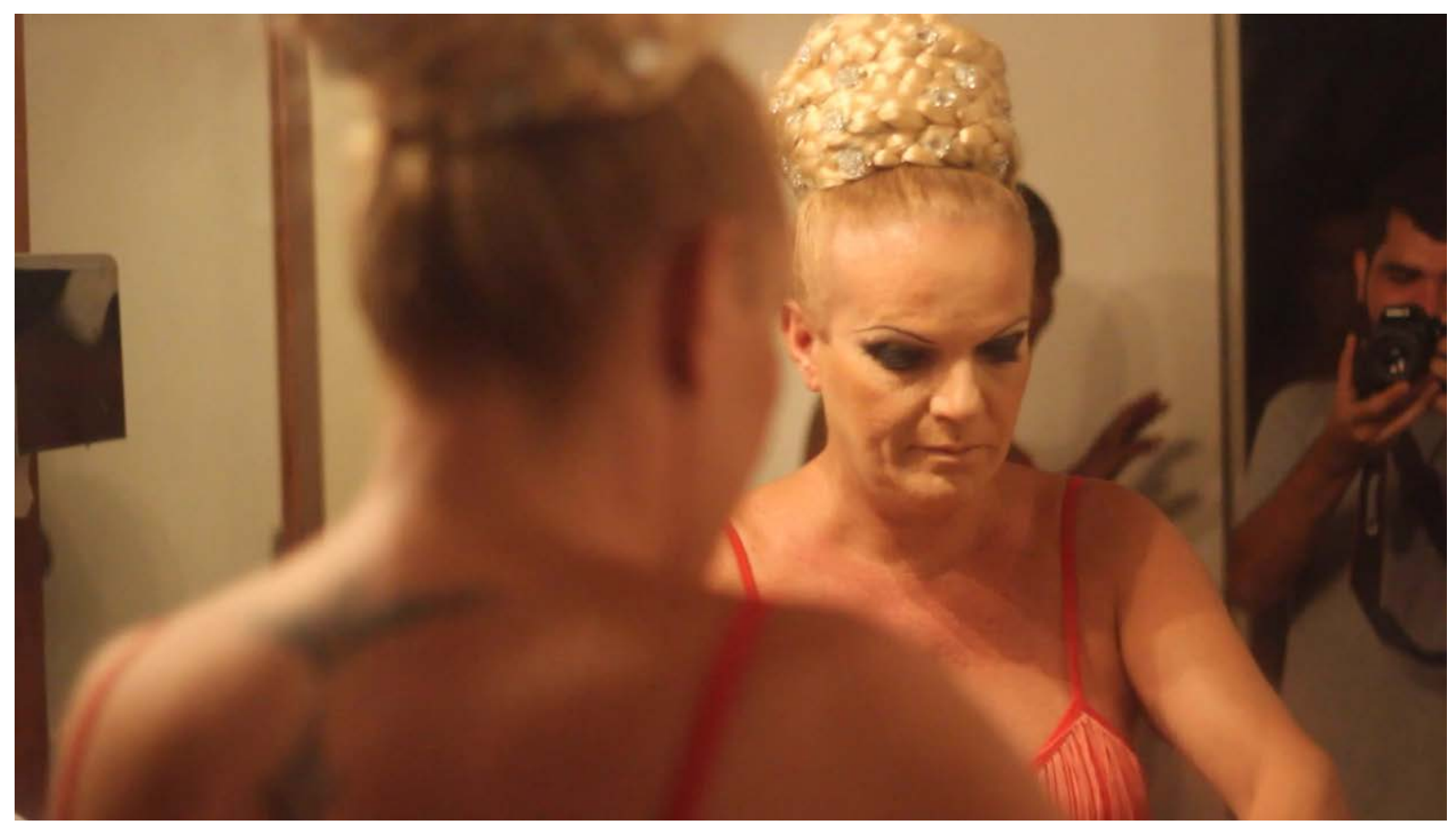

Fotograma 1 (6'47"): Em primeiro plano está Fernanda no camarim do Teatro de Arena no dia do seu primeiro espetáculo no TRANSHOW. Ao fundo, estou eu a filmá-la. Maceió (AL), Brasil. 6 de dezembro de 2014.

Estivemos juntos desde o dia 3 (três) de maio até o dia 7 (sete) do mesmo mês, quando ela viajou para a França. Neste período fizemos coisas triviais, como ida ao hospital, sair para almoçar ou tomar café, fazer compras, ir ao cabeleireiro... Tentei documentar filmicamente a maior parte destas ações. Às vezes quando eu tinha a câmera desligada era a própria Fernanda que pedia-me para ligá-la novamente.

Ao longo da rodagem percebi que aquilo tudo estava a desencadear um outro processo, particular à Fernanda. Pude notar uma melhoria do humor de Fernanda ao longo dos dias em que estivemos juntos. Busquei transpor e evidenciar isso no filme. Propositalmente, durante a montagem, faço um contraponto sobre exatamente este "progresso". Uma das primeiras imagens que são exibidas no filme é quando ela diz que anda ansiosa e cansada (3'25"), na cozinha de sua casa em Paredes. Depois, já próximo do fim daquela narrativa, há uma cena que nos mostra a beber café e pergunto-lhe despropositadamente: "Tás bem, Fernanda?" (12'10"). Logo em seguida, ela responde-me:

De ontem para hoje estou bem melhor, graças a Deus. Depois dos barbitúricos renovados, a mona acordou bem. Graças a Deus. Que continue assim. Agora é só trabalhar o meu psicológico e pronto. E comer! Mas eu acho que assim... Quando você 
tá em companhia de pessoas agradáveis, que você se sente bem, não vem momento de depressão e tristeza... Eu acho que deve ser isso. Sabia? (Trecho do filme "BRAVO", $\left.2017,12^{\prime} 15^{\prime \prime}\right)$

Este diálogo aconteceu quando já estávamos há alguns dias juntos e ela estava prestes a viajar à França, um dia depois de sua consulta médica em Lisboa. Foram dias intensos que - sem querer parecer presunçoso ou superestimar a capacidade da câmera ou do ato de filmar - consegui sentir quase que um efeito analgésico em Fernanda causado pelo nosso encontro e pela funcionalidade da câmera no meio de todo aquele processo.

\section{POTENCIALIDADES DO «ENCONTRO»}

A câmera parecia, de certo modo, um fio condutor entre ela e o restante do mundo, onde era preciso muitas vezes demarcar detalhadamente certas fronteiras na sua fala e na sua performance como forma de afirmação identitária numa preocupação - legítima relacionada com a eventual propagação da sua imagem.

David MacDougall, ao falar sobre o seu filme Familiar Places (1980), realizado em Cape York, Austrália, em 1977 com o grupo Naponans, aponta o fato da comunidade etnografada enxergar a realização do filme como uma ajuda no processo de retomada de suas terras consideradas tradicionais. "Há uma consciência do filme em si como um canal de comunicação" (MACDOUGALL, 1997, p. 102), descreve o antropólogo e cineasta. Portanto, neste sentido, ao longo do processo de realização de «BRAVO» (2017), Fernanda obviamente falava diretamente comigo, entretanto é possível identificar que a sua fala também direcionava-se a outros públicos - o corpo do espectador. Conscientemente ou não, ela sabia a importância e a dimensão política do seu discurso e da sua imagem corporal (MACDOUGALL, 2006) na elaboração do filme.

Em diversas passagens do filme busco tornar evidente a minha relação com Fernanda. Além da sua presença, é marcante a existência de uma segunda pessoa no processo - eu - como forma de registrar um encontro dialógico (BUBER, 2003), sendo a qualidade deste encontro uma das características fundamentais na realização de um documentário antropológico (FREIRE, 2009, p. 82).

Há, portanto, na realização de todo documentário, uma relação de poder, quer o realizador queira ou não, em que ele, realizador, detém o domínio sobre um processo em construção, enquanto as pessoas filmadas the são submetidas. (FREIRE, 2009, $p$. 87).

Durante a realização de um filme documental, Marcius Freire (2009) refere-se ao poder inquestionável de quem detém a câmera, independentemente dos diferentes processos de compartilhamento que resultaram do trabalho. Como tentativa de amenizar a autoridade exercida por quem realiza o filme, busquei ao máximo que Fernanda participasse 
ativamente dos segmentos que levaram à criação desta narrativa audiovisual, incluindo a montagem, que geralmente é o momento em que, de acordo com Freire (2009), o realizador assume notoriamente o seu poder sobre aquilo que está a ser produzido.

Ao pensarmos a montagem como um ordenamento de imagens num sentido reflexivo, esta torna-se um momento fundamental na concepção do filme como um produto resultante de um encontro dialógico. Durante este período Fernanda já estava na França e as nossas conversas passaram a ser mediadas principalmente por videochamadas através de plataformas online. A narrativa foi alterando-se à medida que foi feita a decupagem das cenas e dialogávamos acerca do que seria ou não exibido no filme, sendo um processo de negociação mútua.

Tal exercício associo à prática da Antropologia Partilhada, consolidada por Jean Rouch durante o processo de realização de seu filme Bataille sur le Grand Fleuve (ROUCH, 1951), quando o antropólogo, em 1951, enquanto estava em Níger, na África, exibiu o seu filme para os seus interlocutores e é questionado acerca de uma música numa cena de caça a hipopótamos. Naquele momento, alguém disse-lhe que o som sobre a imagem iria afastar os animais do local onde a caça estava a acontecer. Este diálogo fez com que Rouch repensasse a montagem do filme e, desta forma, acabou por retirar o som da cena. Posteriormente, em 1993, o antropólogo escreveu indignado sobre o quão absurdo e injusto é escrever livros inteiros sobre pessoas e estas pessoas nunca terem contato com tais informações. Рага Jean Rouch, o cinema permite ao etnógrafo partilhar mais facilmente a sua pesquisa antropológica com os seus sujeitos-atores (ROUCH, 1993).

Muitos antes disso, o cineasta Robert Flaherty - uma das grandes influências de Rouch - realizou o filme que viria marcar a história do cinema documental e antropológico/etnográfico, o clássico Nanook of the North (1922), realizado a partir da observação participante. Rodado em 1922, o filme documenta através da imagem videográfica o cotidiano do caçador esquimó Nanook e da sua família, que viveram em Hudson Bay, no nordeste do Canadá. Ao longo do filme, o realizador vai descrevendo através de textos escritos o que vai acontecendo. Inicialmente, a sua proposta era documentar as suas expedições pelo norte do Canadá acompanhado por esquimós, entre 1910 e 1916. Ele informa que esta primeira versão do filme falhou drasticamente em termos de material filmado. Logo em seguida, voltou ao campo e, desta vez, optou por focar o filme em uma única pessoa - Nanook, sendo ele um exemplo representativo do estilo de vida daquelas comunidades.

I went north again, this time solely to make a film. I took with me not only cameras, but apparatus to print and project my results as they were being made, so many character and his family could understand and appreciate what I was doing. (Trecho do filme Nanook of the North, 1922, 01'20"). 
Flaherty deu início ao que, décadas depois, Rouch chamou de Antropologia Partilhada. Dessa forma, Nanook of the North (1922) pode ser considerado um trabalho colaborativo ao passo em que foi construído através de um diálogo com quem estava a ser representado nas imagens, como é justificado pelo cineasta no trecho acima exibido nos primeiros minutos do filme.

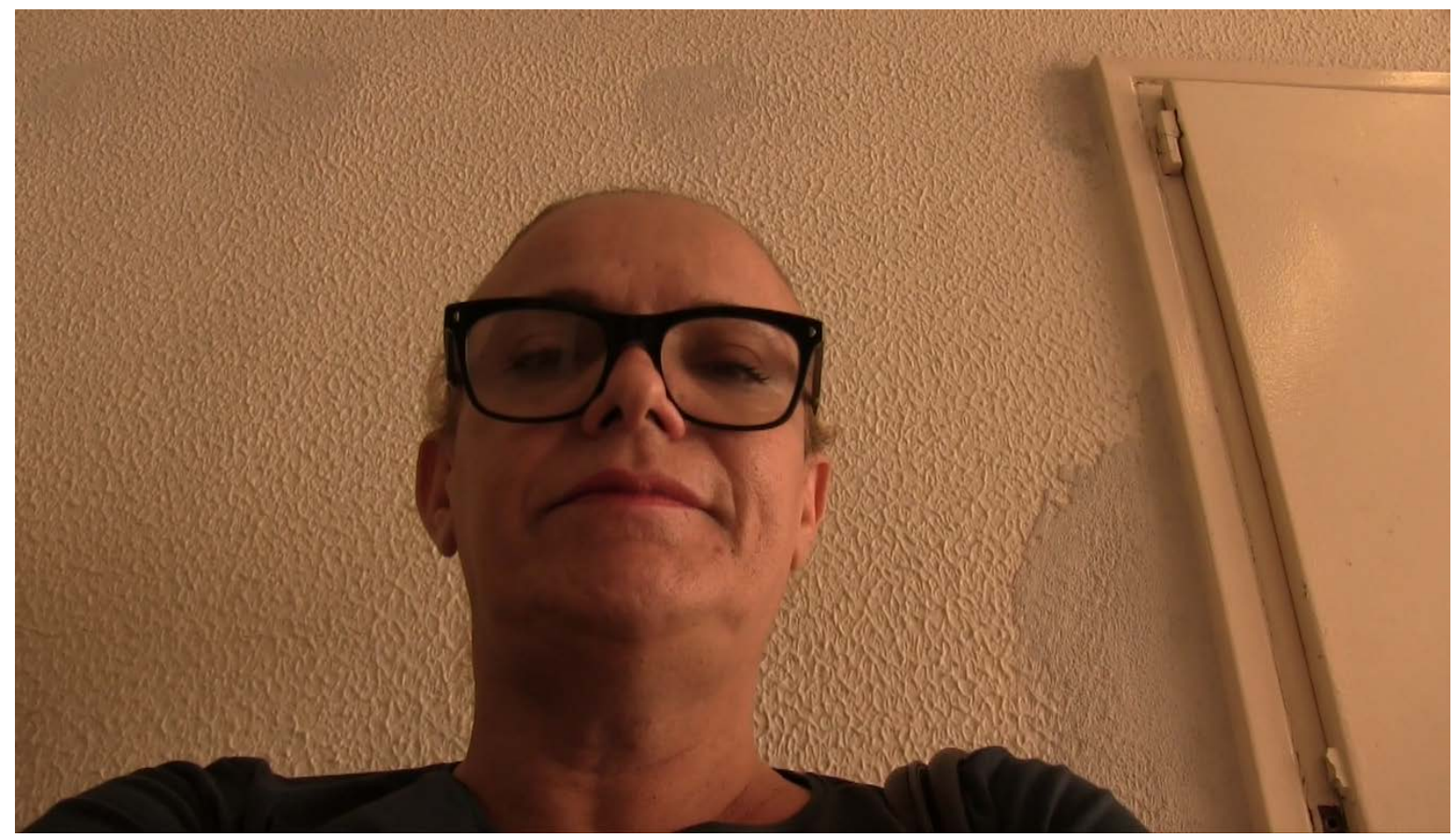

Fotograma 2 (10'50"): Fernanda com a câmera em suas mãos direcionando-a a si mesma, após consulta no Hospital Santo António dos Capuchos. Lisboa, Portugal. Maio, 4, 2017.

Neste sentido, descrevo a minha experiência fílmica com Fernanda - desde a préprodução, passando pela rodagem e, por fim, a montagem - como um processo colaborativo (DEGARROD, 2013) elaborado a partir do método da antropologia partilhada (ROUCH, 1993). Objetivamente, como um dos exemplos desta construção partilhada, dentre as imagens apresentadas no filme há uma cena em que passo a câmera para a mão de Fernanda enquanto estamos no hospital, pois tive que voltar à sala de espera para buscar o seu casaco que havia sido esquecido lá (10'30"). Antes de entregar-lhe a câmera, eu disse-lhe apenas: "Fala aí com a câmera...". Fora da minha presença e digirindo-se diretamente para a câmera, Fernanda fez a seguinte declaração:

Oi, câmera... Aqui... Terminei minha consulta. Praticamente já era aquilo que eu esperava, né? Fui diagnosticada com excesso de estresse. Com excesso de... ansiedade... e... Minha estadia em Portugal vai ser encurtada, porque... é... muito tempo aqui poderia me fazer mal. Então eu vou ver se encurto a minha passagem para poder ir para o Brasil. Tá?! (Trecho do filme "BRAVO», 2017, 10'35").

Quando reapareci a sua frente, ela repassou-me a câmera e disse-me: "Já dei o meu depoimento. É tudo depoimento." 
Há um significado neste ato, no sentido em que, ao transferir-lhe a câmera, também the é transferido o poder de possuir a câmera e direcioná-la para onde ela preferir, dirigindoa, neste caso, para si mesma. O ato de possuir a câmera por parte do realizador pode ser interpretado como uma forma de exerção do poder simbólico (BOURDIEU, 1989, p. 7), ao passo em que este manifesta-se muitas vezes de maneira irreconhecível e legitimada. Desta forma, a partir desta descentralização, Fernanda passa a ter a possibilidade de autorepresentar-se através do dispositivo fílmico, construindo e demarcando a sua autoimagem.

Para Macdougall, "vemos com nosso corpo, e qualquer imagem que façamos carrega a marca dele, ou seja, do nosso ser, bem como dos signifcados que pretendemos comunicar" (MACDOUGALL, 2009, p. 63). Nesta construção, objetivei estabelecer níveis de sensibilidade para além do que foi visualmente representado. Assim, associo este filme não unicamente a pessoa de Fernanda Bravo, e sim também a uma parcela significativa das mulheres transexuais que vieram do Brasil e estão inseridas no contexto português

\section{CONSIDERAÇÕES FINAIS}

Ao decorrer desta experiência percebi-me que, além do fator sócio-político e da preocupação constante nas formas de representação durante a narrativa, o filme foi moldando-se e, por isto, modificando o seu roteiro - que foi construindo-se à medida que filmávamos. Filmar a Fernanda possibilitou-me, de forma criativa, repensar as minhas práticas tanto na antropologia, como também no audiovisual.

A antropóloga e cineasta vietnamita Trinh T Minh-ha, em uma entrevista cedida à Nancy N. Chen, fala do seu trabalho visual e a linguagem que utiliza para estruturá-lo. Рara ela, o mais importante não é falar sobre determinado tema como se quem está a filmar estivesse longe daquela realidade, e sim to speak nearby (MINH-HÁ in CHEN, 1992, p. 87). Por estar a filmar e inserida/o de alguma forma naquele contexto, a/o cineasta e/ou antropóloga/o incorpora-se aquele instante e acaba também por fazer parte daquele contexto.

A partir destas notas tento justificar que um filme documental pode não ser um processo unilateral e que o produto final deste filme está intrinsecamente relacionado com a relação estabelecida entre ambas as partes. O filme pode ser o resultado de um diálogo entre quem filma e quem é filmada/o - e estes papéis nem sempre são definidos de forma tão linear. Filmes são encontros, como disse Rouch alguma vez. 


\section{REFERÊNCIAS}

BÄCKSTRÖM, Bárbara; CARVALHO, Amélia; INGLÊS, Urbana. "Imigração e saúde - 0 Gabinete de Saúde do CNAI enquanto observatório para o estudo das condições de acesso dos imigrantes aos serviços de saúde", Revista Migrações, n. ${ }^{\circ}$ 4, Lisboa: ACIDI, p. 161-189, 2009.

BOURDIEU, P. 0 poder simbólico. Bertrand Brasil S.A. Rio de Janeiro, 1989.

BUBER, Martin. Eu e tu. São Paulo: Centauro, 2003.

CAIUBY NOVAES, Sylvia. "A construção de imagens na pesquisa de campo em Antropologia". Iluminuras, Porto Alegre, v.13, p.11-29, 2012.

CHEN, Nancy N. "Speaking Nearby:" A Conversation with Trinh T. Minh-ha". Visual Anthropology Review, The University of California, Berkeley: Volume 8, Number 1, p. 82-91, 1992.

DEGARROD, Lydia Nakashima. "Collaborative art and the emergence and development of ethnographic knowledge and empathy", Critical Arts: South-North Cultural and Media Studies, 27:5, 2013, p. 322-340.

FLAHERTY, Robert. Nanook of the North [Filme]. Canadá: P\&B, 79 minutos, 1922.

FREIRE, M. Jean Rouch e a ética do encontro. Devires (Universidade Federal de Minas Gerais), v. 6, p. 80-97, 2009.

MACDOUGALL, David. De quem é essa estória? Cadernos de Antropologia e Imagem, n0 5, p. 93-105. Rio de Janeiro, 1997.

. Familiar Places [Filme]. Queensland (AUS): cor, 50 minutos, 1980.

. Significado e Ser. In: BARBOSA, CUNHA \& HIKIJI (orgs). Imagemconhecimento:

Antropologia, cinema e outros diálogos. Campinas: Papirus, 2009.

. The Corporeal Image. Princeton, New Jersey: Princeton University Press, 2006.

PONTES, Alfredo M. BRAVO [Filme]. Lisboa (PT) / Maceió (BR): cor, 13 minutos, 2017.

ROUCH, Jean. Bataille sur le Grand Fleuve [Filme]. CFE/CNRS. Paris (FR): 16mm, cor, 25 minutos, 1951. . Entrevista: Jean Rouch, 54 anos sem tripé. Cadernos de Antropologia e Imagem $n^{0} 1$, Rio de Janeiro: UERJ, p. 65-74, 1995.

. Nanook of the North [Filme]. Canadá: P\&B, 1h92min., 1922.

. Os 'pais fundadores'. Dos 'ancestrais totêmicos' aos pesquisadores de amanhã. Mostra Internacional do Filme Etnográfico - Catalogo. Rio de Janeiro, Centro Cultural Banco do Brasil, Interior Produções, 1993.

RUSSELL, Catherine. Experimental Ethnography: The Work of Film in the Age of Video. Durham: Duke University Press, 1999.

SILVA, Carolina Cavalcante Lins. Da luta pela vida à busca pela cidadania: 0 ativismo político de travestis e transexuais na cidade de Maceió-AL. Dissertação (Mestrado em Psicologia), Programa de Pós-Graduação em Psicologia, Instituto de Psicologia, Universidade Federal de Alagoas. Maceió, 2016. 